\title{
BMJ Global Health Mass azithromycin administration: considerations in an increasingly resistant world
}

\author{
Yogesh Hooda, ${ }^{1,2}$ Arif M Tanmoy, ${ }^{1}$ Mohammad Saiful Islam Sajib, ${ }^{1}$ \\ Senjuti Saha (D) ${ }^{1}$
}

To cite: Hooda Y,

Tanmoy AM, Sajib MSI, et al. Mass azithromycin administration: considerations in an increasingly resistant world. BMJ Global Health 2020;5:e002446. doi:10.1136/ bmjgh-2020-002446

Handling editor Seye Abimbola

Received 29 February 2020

Revised 30 April 2020

Accepted 9 May 2020

Check for updates

C Author(s) (or their employer(s)) 2020. Re-use permitted under CC BY-NC. No commercial re-use. See rights and permissions. Published by BMJ.

${ }^{1}$ Child Health Research Foundation, Dhaka, Bangladesh ${ }^{2}$ MRC Laboratory of Molecular Biology, Cambridge, UK

Correspondence to Dr Senjuti Saha; senjutisaha@chrfbd.org
Azithromycin is an oral macrolide discovered in 1980 and approved for medical use in $1988 .{ }^{1}$ This relatively inexpensive antibiotic is often deemed as a wonder drug due to its safety and effectiveness against parasitic and helminth infections, in addition to a wide range of bacterial infections. In the early 2000s, biannual administration of azithromycin (mass drug administration, MDA) for trachoma control was found to reduce all-cause mortality by almost $49 \% .^{2}$ These encouraging results, presumably due to reduction in respiratory and diarrhoeal infections ${ }^{34}$ and malaria, ${ }^{5}$ led to the placebo-controlled, double-blinded, cluster-randomised MORDOR-I trial (Macrolides Oraux pour Réduire les Décès avec un Oeil sur la Résistance) in Niger, Malawi and Tanzania covering 190238 children. $^{6}$ An overall $13.5 \%$ reduction in child mortality was observed in azithromycin versus placebo communities; however, the effect was largely driven by findings in Niger $(18.1 \%)$, with minimal impact in Malawi $(5.7 \%)$ and Tanzania $(3.4 \%)$. While the mechanism of azithromycin's effect on childhood mortality is not fully understood, the overall success of the MORDOR-I trial has led to additional trials in various other countries, including follow-up trials in Niger and Burkina Faso (NCT03676751). Notably, there are ongoing clinical trials in Pakistan (NCT03564652 and NCT04012177) and a large-scale trial that will provide azithromycin to all children at risk of diarrhoea in seven countries including Pakistan, India and Bangladesh (NCT03130114).

While a silver bullet against childhood mortality is highly desirable for vulnerable populations, unintended consequences like a surge in antimicrobial resistance (AMR) on MDA remain a major concern. This is especially pertinent to the case of azithromycin as this antibiotic is becoming the first line of treatment of a variety of bacterial infections.
Summary box

Recent studies have shown that mass administration of azithromycin in some areas can lead to reduction in childhood mortality, which in turn has led to additional large-scale trials in many parts of the world.

- We provide evidence for the emergence of novel azithromycin resistance mechanisms in common bacterial pathogens like Salmonella, arguing that the appealing positive effects of mass drug administration might diminish with increasing azithromycin resistance.

- While a silver bullet against childhood mortality is highly desirable, given the alarming rise in antimicrobial resistance and the drying pipeline of novel drugs, the opportunity costs of mass administration should be considered with utmost caution.

- Future studies and trials of mass azithromycin administration should include methods for early detection of azithromycin resistance such that preventative measures can be implemented, in case azithromycin resistance begins to spread.

In 2016, an extensively drug-resistant (XDR) strain of Salmonella Typhi caused a large outbreak of typhoid fever in Pakistan affecting over 10000 people. ${ }^{7}$ Resistant to all oral antibiotics except azithromycin, this ongoing outbreak has become a cause of serious concern in the global health community. Adding to this concern are recent reports of azithromycin-resistant Salmonella Typhi strains from Pakistan's neighbouring countries, India and Bangladesh. ${ }^{8}$ Emergence of pan-oral drug-resistant (PoDR) Typhi in Pakistan or in any typhoid endemic country will severely impair our ability to contain this disease. At present, majority of patients with typhoid are treated with oral antibiotics in the community or in the outpatient department. Emergence of PoDR Typhi would shift the treatment from the outpatient to inpatient departments. Considering the high burden of typhoid infections every year and 
the limited number of hospital beds, PoDR Typhi may increase the current mortality rate of $<1 \%$ to closer to that seen in the preantibiotic era $(\sim 30 \%)$. In addition to preventative measures like vaccine, and water, sanitation and hygiene (WASH) interventions, the crusade against the emergence of PoDR Typhi calls for judicious use of azithromycin. Hence in this essay, we advocate for utmost discretion moving forward and list key considerations that should be taken into account while designing and implementing azithromycin MDA studies.

Like other macrolides, azithromycin targets the P-site of the 50S subunit of bacterial ribosome, one of the most conserved biomolecules in bacteria. Various molecular mechanisms of azithromycin resistance have been identified in different bacterial species. ${ }^{1}$ These include acquisition of target modifying enzymes (such as methyltransferases) or macrolide detoxifying enzymes (such as esterases, glycosyltransferases and phosphotransferases) that can be transferred through horizontal gene transfer to other bacterial species. Additionally, increased expression of efflux pumps has also been found to contribute to azithromycin resistance. ${ }^{18}$ A follow-up study to MORDOR-I found an increase in isolation of macrolide-resistant pneumococcus $(12.3 \%$ vs $2.9 \%)$ from the nasopharyngeal cavity, and a higher presence of known macrolide resistance markers at both DNA (68\% vs $46.7 \%)$ and RNA (16.7\% vs $2.7 \%$ ) levels in the intestinal flora of children treated with azithromycin at the Nigerien site. ${ }^{9}$ The gut microbiome is a reservoir of resistance, and instances of transfer of resistance markers between resident gut bacteria and pathogenic bacterial species are common. Bacterial AMR can very quickly spread globally through dissemination and horizontal gene transfer between different bacterial species. ${ }^{10}$ The spread of azithromycin resistance would not only lead to reduction in the efficacy of MDA over time, but also steal one of the few remaining options of cost-effective antibiotic to treat specific, life-threatening bacterial infections. While two ongoing MDA trials will monitor azithromycin resistance mechanisms (NCT03676751 and NCT03130114), we recommend that all future studies should include methods for early AMR detection such that preventative measures can be implemented, in case azithromycin resistance begins to spread.

Another key concern is that current molecular techniques may grossly underestimate azithromycin resistance as the known resistance mechanisms most likely represent a proportion of all the potential modes of azithromycin resistance. Recently, our group demonstrated that a point mutation at position $717(\mathrm{R} 717 \mathrm{Q} / \mathrm{L})$ in the efflux pump AcrB can lead to azithromycin resistance in Salmonella Typhi and Paratyphi A (causative agent of paratyphoid fever). ${ }^{8}$ The MORDOR studies did not look at the abundance of AcrB variants in the studied population. ${ }^{9}$ To determine the global distribution of this particular mutation, we searched for the AcrB R717Q/L variants in sequenced strains of typhoidal (Typhi and Paratyphi A) and major non-typhoidal serovars (Typhimurium and Enteritidis) of Salmonella. The latter two serovars are the most common causes of non-typhoidal salmonellosis that can lead to case fatality rates of $20 \%-25 \%$ in sub-Saharan Africa and azithromycin is often used as the drug of choice. ${ }^{11}$ Given their genomic similarity to typhoidal Salmonella, AcrB R717Q/L mutations are likely to cause azithromycin resistance in these serovars. In total, we searched 49115 Salmonella genomes (Enteritidis ( $\mathrm{n}=23661)$, Typhimurium $(\mathrm{n}=17076)$, Typhi $(\mathrm{n}=7136)$ and Paratyphi A $(\mathrm{n}=1242)$ ) available in EnteroBase, a genome database of enteric bacteria. ${ }^{12}$ The $\mathrm{R} 717 \mathrm{Q} / \mathrm{L}$ mutation was found in 86 strains (Enteritidis $(n=61)$, Typhimurium $(\mathrm{n}=8)$, Typhi $(\mathrm{n}=16)$, Paratyphi A $(\mathrm{n}=1))$. This mutation was most commonly found in the strains from the UK (figure 1), which is not surprising as the UK also had the highest number of sequenced strains $(n=22161)$. As more strains of Salmonella are sequenced from developing countries, especially from sub-Saharan Africa and South Asia, where most MDA trials are under way, we predict that more AcrB R717Q/L mutations will be identified. In addition, as azithromycin usage increases in populations, the acquisition of such novel mechanisms (eg, mutations) may accelerate. These novel mutations will be harder to predict compared with known resistance markers, yet could spread fast globally and to other bacterial species. To overcome these limitations, we need to continuously update the list of potential modes of azithromycin resistance and also help fund basic laboratory and computational/machine-learning studies to estimate the potential routes through which azithromycin resistance may emerge.

Furthermore, when designing studies or interpreting results for MDA trials, it is important to note that antibiotic consumption rates differ between and within countries. The increase in resistance seen in the 2 years of MORDOR-I did not contribute to a decrease in efficacy over the following year during the longer term follow-up in MORDOR-II. ${ }^{13}$ Furthermore, studies conducted after azithromycin MDA for trachoma control showed that when administration was stopped, resistance returned to near-baseline levels. ${ }^{13}$ However, it is important to note that the trachoma control and MORDOR-II studies were primarily conducted in very poor regions of sub-Saharan African countries, where the rates of antibiotic exposure are low. As countries develop, antibiotic consumption, especially over-the-counter antibiotic usage, increases and this can lead to unexpected increase in the rate of acquisition of azithromycin resistance. ${ }^{14}$ Of special concern are places like Pakistan, where due to the outbreak of XDR Typhi azithromycin usage has already shot up. ${ }^{7}$ Largescale azithromycin administration in Pakistan would increase the chance of emergence of PoDR Typhi strains. Hence, in the MDA studies, special attention should be given to pathogens relevant to the local populations. The incidence of typhoid and paratyphoid fever is 549.2 and 219.2 per 100000 in South and South-East Asia, respectively. ${ }^{15}$ The incidence of non-typhoidal Salmonella is 34.3 per 100 000, with mortality rates greater than 100 per 


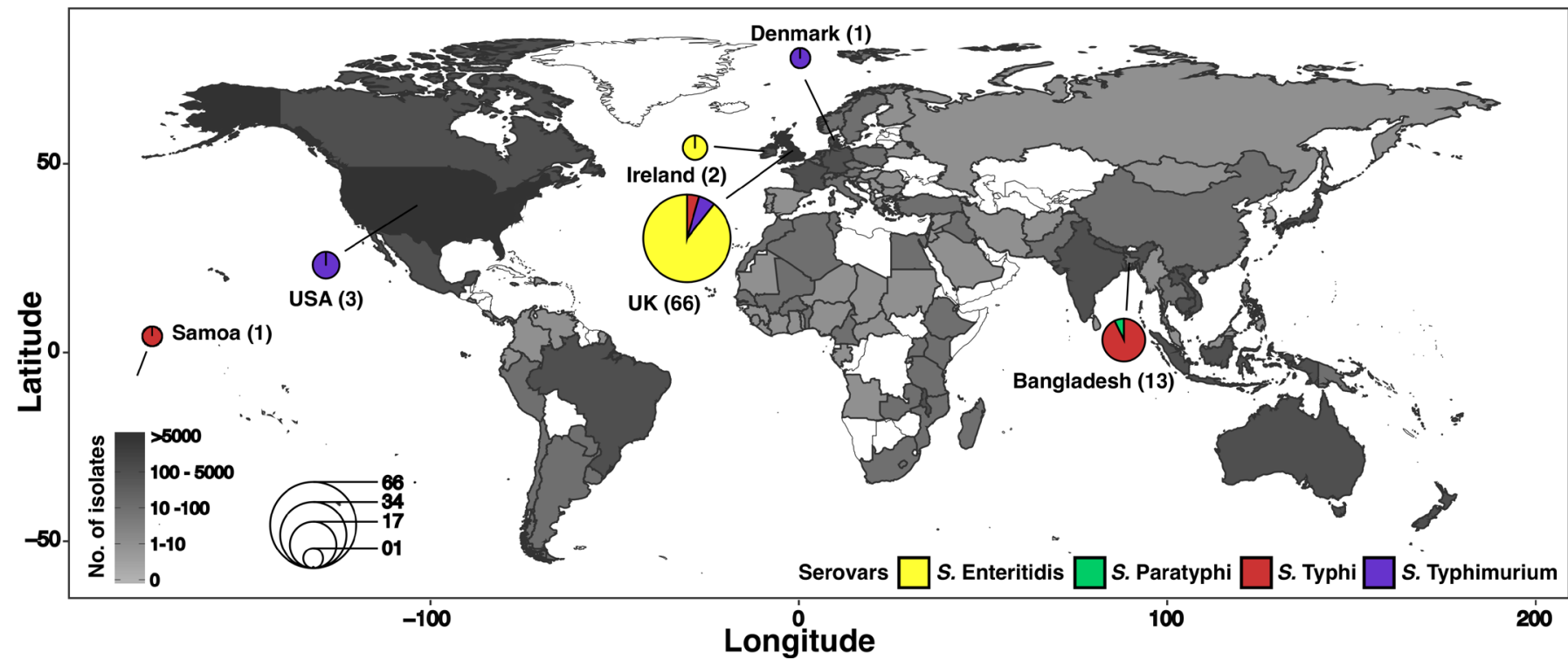

Figure 1 Global distribution of pathogenic Salmonella isolates with AcrB mutations associated with macrolide resistance. Genomes of four pathogenic Salmonella serovars-Enteritidis, Typhimurium, Typhi and Paratyphi A-present in the online database EnteroBase (downloaded May 2019) were screened for the presence of AcrB R717Q/L mutations. The countries are shaded based on the number of strains sequenced, and countries in white had no sequenced Salmonella strains. Countries from which AcrB R717Q/L-containing strains could be identified are highlighted, and the number of strains found in each country is shown as a pie chart, where the size of the pie represents the number of strains identified with mutation and colours represent the different serovars.

million in sub-Saharan countries such as Burkina Faso, Niger and Mali. ${ }^{11}$ Hence, rising azithromycin resistance in Salmonella species is of serious concern and should be monitored in future azithromycin MDA studies.

Lastly, there are many intervention strategies by which childhood mortality can be improved that do not require antibiotic usage. In areas with limited resources the costs of MDA studies may divert resources and attention away from other intervention strategies such as improvements in antenatal and neonatal nutritional supplements, developments in WASH and so on. Future azithromycin MDA studies must be integrated into health systems such that they can strengthen existing or new child survival interventions.

Given the alarming rise in AMR and the drying pipeline of novel drugs, the opportunity costs of MDA should be considered with utmost caution. The appealing positive effects of azithromycin MDA are likely to diminish with the inevitable rise of azithromycin resistance, leaving a narrow window where such strategies can have maximal impact. Indiscriminate use of antibiotics may lead to unrecoverable loss of an extremely precious commodity.

Twitter Senjuti Saha @senjutisaha

Contributors All authors made substantial contributions to the conception of the work, or the acquisition, analysis or interpretation of data, and in drafting or critically revising the work, and approved the final submitted version.

Funding The authors have not declared a specific grant for this research from any funding agency in the public, commercial or not-for-profit sectors.

Competing interests None declared.

Patient consent for publication Not required.

Provenance and peer review Not commissioned; externally peer reviewed.
Data availability statement № additional data are available.

Open access This is an open access article distributed in accordance with the Creative Commons Attribution Non Commercial (CC BY-NC 4.0) license, which permits others to distribute, remix, adapt, build upon this work non-commercially, and license their derivative works on different terms, provided the original work is properly cited, appropriate credit is given, any changes made indicated, and the use is non-commercial. See: http://creativecommons.org/licenses/by-nc/4.0/.

ORCID iD

Senjuti Saha http://orcid.org/0000-0001-6087-6766

\section{REFERENCES}

1 Gomes C, Martínez-Puchol S, Palma N, et al. Macrolide resistance mechanisms in Enterobacteriaceae: focus on azithromycin. Crit Rev Microbiol 2017;43:1-30.

2 Porco TC, Gebre T, Ayele B, et al. Effect of mass distribution of azithromycin for trachoma control on overall mortality in Ethiopian children: a randomized trial. JAMA 2009;302:962-8.

3 Coles CL, Levens J, Seidman JC, et al. Mass distribution of azithromycin for trachoma control is associated with short-term reduction in risk of acute lower respiratory infection in young children. Pediatr Infect Dis J 2012;31:341-6.

4 Coles CL, Seidman JC, Levens J, et al. Association of mass treatment with azithromycin in trachoma-endemic communities with short-term reduced risk of diarrhea in young children. Am J Trop Med Hyg 2011;85:691-6.

5 Schachterle SE, Mtove G, Levens JP, et al. Short-Term malaria reduction by single-dose azithromycin during mass drug administration for trachoma, Tanzania. Emerg Infect Dis 2014;20:941-9.

6 Keenan JD, Bailey RL, West SK, et al. Azithromycin to reduce childhood mortality in sub-Saharan Africa. N Engl J Med 2018;378:1583-92.

7 Qamar FN, Yousafzai MT, Khalid M, et al. Outbreak investigation of ceftriaxone-resistant Salmonella enterica serotype typhi and its risk factors among the general population in Hyderabad, Pakistan: a matched case-control study. Lancet Infect Dis 2018;18:1368-76.

8 Hooda Y, Sajib MSI, Rahman H, et al. Molecular mechanism of azithromycin resistance among typhoidal Salmonella strains in 
Bangladesh identified through passive pediatric surveillance. PLOS Negl Trop Dis 2019;13:e0007868.

9 Doan T, Hinterwirth A, Worden L, et al. Gut microbiome alteration in MORDOR I: a community-randomized trial of mass azithromycin distribution. Nat Med 2019;25:1370-6.

10 Baker S, Thomson N, Weill F-X, et al. Genomic insights into the emergence and spread of antimicrobial-resistant bacterial pathogens. Science 2018;360:733-8.

11 GBD 2017 Non-Typhoidal Salmonella Invasive Disease Collaborators. The global burden of non-typhoidal Salmonella invasive disease: a systematic analysis for the global burden of disease study 2017. Lancet Infect Dis 2019:19:1312-24.
12 Alikhan N-F, Zhou Z, Sergeant MJ, et al. A genomic overview of the population structure of Salmonella. PLoS Genet 2018;14:e1007261.

13 Keenan JD, Arzika AM, Maliki R, et al. Longer-Term assessment of azithromycin for reducing childhood mortality in Africa. N Engl J Med 2019;380:2207-14.

14 Klein EY, Van Boeckel TP, Martinez EM, et al. Global increase and geographic convergence in antibiotic consumption between 2000 and 2015. Proc Natl Acad Sci U S A 2018;115:E3463-70.

15 GBD 2017 Typhoid and Paratyphoid Collaborators. The global burden of typhoid and paratyphoid fevers: a systematic analysis for the global burden of disease study 2017. Lancet Infect Dis 2019;19:369-81. 